Article

\title{
Oxygen Reduction Electrocatalysts Based on Coupled Iron Nitride Nanoparticles with Nitrogen-Doped Carbon
}

\author{
Min Jung Park ${ }^{1,2,+}$, Jin Hee Lee ${ }^{1,+}$, K. P. S. S. Hembram ${ }^{3}$, Kwang-Ryeol Lee ${ }^{3}$, Sang Soo Han ${ }^{3}$, \\ Chang Won Yoon ${ }^{1,4}$, Suk-Woo Nam ${ }^{1,2,5}$ and Jin Young Kim ${ }^{1, *}$ \\ 1 Fuel Cell Research Center, Korea Institute of Science and Technology, Seongbuk-gu, Seoul 02792, Korea; \\ mjpark@kist.re.kr (M.J.P.); sinhwa1030@gmail.com (J.H.L.); cwyoon@kist.re.kr (C.W.Y.); \\ swn@kist.re.kr (S.-W.N.) \\ 2 Department of Energy and Environmental Engineering, Korea University of Science and Technology, \\ Daejeon 34113, Korea \\ 3 Computational Science Research Center, Korea Institute of Science and Technology (KIST), \\ Seongbuk-gu, Seoul 02792, Korea; hembramhembram@gmail.com (K.P.S.S.H.); krlee@kist.re.kr (K.-R.L.); \\ sangsoo@kist.re.kr (S.S.H.) \\ 4 Department of Clean Energy and Chemical Engineering, Korea University of Science and Technology, \\ Daejeon 34113, Korea \\ 5 Green School, Korea University, 145, Anam-ro, Seongbuk-gu, Seoul 136-701, Korea \\ * Correspondence: jinykim@kist.re.kr; Tel.: +82-2-958-5294 \\ + These authors contributed equally to this work.
}

Academic Editors: Vincenzo Baglio and David Sebastián

Received: 14 April 2016; Accepted: 6 June 2016; Published: 15 June 2016

\begin{abstract}
Aimed at developing a highly active and stable non-precious metal electrocatalyst for oxygen reduction reaction (ORR), a novel $\mathrm{Fe}_{x} \mathrm{~N}_{y} / \mathrm{NC}$ nanocomposite-that is composed of highly dispersed iron nitride nanoparticles supported on nitrogen-doped carbon (NC) - was prepared by pyrolyzing carbon black with an iron-containing precursor in an $\mathrm{NH}_{3}$ atmosphere. The influence of the various synthetic parameters such as the Fe precursor, Fe content, pyrolysis temperature and pyrolysis time on ORR performance of the prepared iron nitride nanoparticles was investigated. The formed phases were determined by experimental and simulated X-ray diffraction (XRD) of numerous iron nitride species. We found that $\mathrm{Fe}_{3} \mathrm{~N}$ phase creates superactive non-metallic catalytic sites for ORR that are more active than those of the constituents. The optimized $\mathrm{Fe}_{3} \mathrm{~N} / \mathrm{NC}$ nanocomposite exhibited excellent ORR activity and a direct four-electron pathway in alkaline solution. Furthermore, the hybrid material showed outstanding catalytic durability in alkaline electrolyte, even after 4,000 potential cycles.
\end{abstract}

Keywords: oxygen reduction reaction; non-precious metal electrocatalysts; Iron nitride; nitrogen-doped carbon

\section{Introduction}

Over the last few decades, low temperature polymer electrolyte membrane fuel cells (PEMFCs) have been recognized as a promising substitute to the current fossil fuel based power generation system [1,2]. Despite extensive efforts to improve performance of PEMFCs, enhancement of sluggish kinetics of oxygen reduction reaction (ORR) has remained a major challenge. Thus far, Pt derived materials have been considered state of the art electrocatalysts for ORR. [3,4] Nevertheless, the high price and instability of $\mathrm{Pt}$ catalysts in various fuel cell operation conditions limit practical applications of PEMFCs. 
Development of efficient non-precious metal electrocatalysts is thus a topic of great interest in order to commercialize PEMFCs. However, although performance of such catalysts is continuously increasing, the active species responsible for the activation and reduction of adsorbed oxygen molecules are not fully understood yet.

In recent years, it is suggested that that novel materials substituting for $\mathrm{Pt}$ are non-precious $\mathrm{Fe}$ or Co metals embedded within an $\mathrm{N}$-doped carbon (NC) matrix. Inexpensive Fe and/or Co constitute the catalytically active center, while NC materials provide enhanced electron mobility and oxygen adsorption capacity, which in turn, improve electrocatalytic activity as well as durability [5]. Iron carbide $\left(\mathrm{Fe}_{x} \mathrm{C}_{y}\right)$ [6-9], iron oxide $\left(\mathrm{Fe}_{x} \mathrm{O}_{y}\right)$ [10,11], and iron bonded with multiple nitrogen atoms [12] have been suggested as plausible active structures for ORR. However, the complexities of creating the desired bond configuration and characterization of the specific Fe species, has resulted in difficulties improving the materials overall catalytic activity in the electrocatalysts.

Herein, we report a facile, one-step synthetic route that leads to a novel precious-metal-free ORR electrocatalyst composed of iron nitride $\left(\mathrm{Fe}_{x} \mathrm{~N}_{y}\right)$ nanoparticles supported on $\mathrm{NC}\left(\mathrm{Fe}_{x} \mathrm{~N}_{y} / \mathrm{NC}\right)$. Various analytical techniques were employed to elucidate catalytically active sites responsible for the ORR performance. The strong correlation between the $\mathrm{Fe}_{x} \mathrm{~N}_{y}$ phases and ORR activity was proven by experimental and theoretical studies. For electrocatalytic performance, we show that $\mathrm{Fe}_{3} \mathrm{~N} / \mathrm{NC}$ hybrid material exhibits a high ORR activity (half-wave potential $\sim 0.77 \mathrm{~V}$ ) and low $\mathrm{HO}_{2}{ }^{-}(<5 \%$ ) yield in alkaline medium. The prepared electrocatalysts exhibited a direct four-electron ORR pathway and superior stability in an alkaline medium. The proposed synthetic route is low-cost and scalable, providing a feasible method for the development of highly efficient non-precious metal electrocatalysts.

\section{Results and Discussions}

The $\mathrm{Fe}_{x} \mathrm{~N}_{y} / \mathrm{NC}$ catalyst was synthesized through high-temperature pyrolysis of the precursor containing the mixture of the Fe salt and carbon black in an $\mathrm{NH}_{3}$ atmosphere (Scheme 1). The catalyst structure contains a few ten nanometer-sized $\mathrm{Fe}_{x} \mathrm{~N}_{y}$ nanoparticles and NCs with sizes in the range of hundreds of nanometers. Most of the $\mathrm{Fe}_{x} \mathrm{~N}_{y}$ nanoparticles are well dispersed on the NCs. Importantly, the composites showed high inertness under harsh electrochemical conditions, as well as high surface area $\left(1110 \mathrm{~m}^{2} \mathrm{~g}^{-1}\right)$ and electrical conductivity $\left(0.112 \mathrm{~S} \cdot \mathrm{cm}^{-1}\right)$, which are comparable to those of commercial carbon black products (surface area: $1350 \mathrm{~m}^{2} \mathrm{~g}^{-1}$, and electrical conductivity: $0.092 \mathrm{~S} \cdot \mathrm{cm}^{-1}$ ) and beneficial for a number of electrochemical applications. Moreover, the synthetic approach allowed for the low-cost, large-scale production of $\mathrm{Fe}_{x} \mathrm{~N}_{y} / \mathrm{NC}$ electrocatalysts. The structural phase of $\mathrm{Fe}_{x} \mathrm{~N}_{y}$ prepared by heat-treatment has been reported to depend on preparation conditions. [13-15] Therefore, in order to characterize high-performance $\mathrm{Fe}_{x} \mathrm{~N}_{y} / \mathrm{NC}$ electrocatalysts, a series of synthetic parameters that could influence the ORR activity, including the types of Fe salts used, Fe content, heat-treatment temperature, and pyrolysis time were investigated. ORR behaviors of all the catalysts prepared under varying synthetic parameters were compared in $0.1 \mathrm{M} \mathrm{KOH}$ solution (Figure 1).
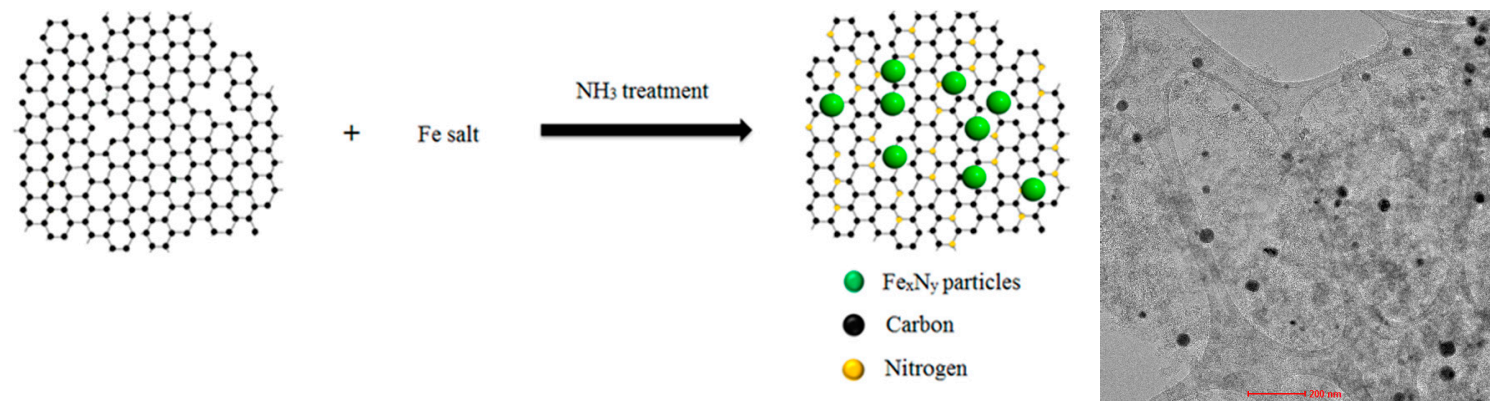

Scheme 1. Illustration of $\mathrm{Fe}_{x} \mathrm{~N}_{y}$ /nanocomposite (NC) synthesis. 

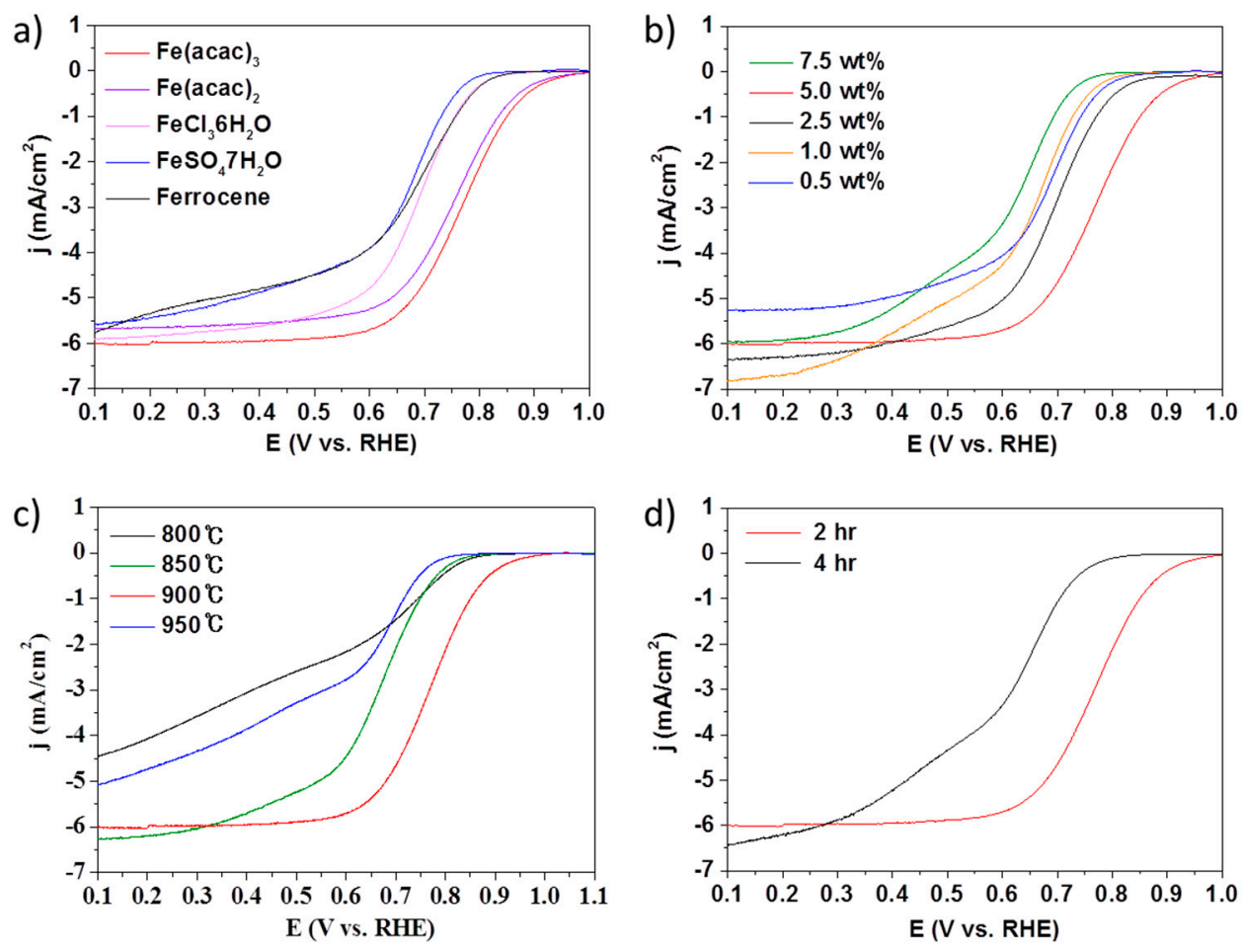

Figure 1. Linear sweep voltammetry curves of oxygen reduction reaction (ORR) in $0.1 \mathrm{M} \mathrm{KOH}$ catalyzed by $\mathrm{Fe}_{x} \mathrm{~N}_{y} / \mathrm{NC}$ prepared by altering synthetic conditions. (a) Fe source, (b) Fe contents, (c) pyrolysis temperature, and (d) pyrolysis time.

For the standard synthesis, $\mathrm{Fe}(\mathrm{acac})_{3}$ and carbon black mixture were pyrolyzed at $900{ }^{\circ} \mathrm{C}$ for $2 \mathrm{~h}$ to give $5 \mathrm{wt}$. \% Fe contents of the catalyst. To test the influence of the aforementioned parameters of the $\mathrm{Fe}_{x} \mathrm{~N}_{y} / \mathrm{NC}$ catalysts, synthetic conditions were altered one by one from the standard condition. The catalysts without Fe and/or nitrogen were also prepared for the comparison. The counter anion of Fe precursors prominently influenced the ORR activity of the final catalysts (Figure 1a). The catalyst synthesized using $\mathrm{Fe}(\mathrm{acac})_{3}$ showed the highest ORR activity among the five Fe precursors tested. The higher catalytic performance of the catalyst prepared using $\mathrm{Fe}(\mathrm{acac})_{3}$, as opposed to $\mathrm{Fe}(\mathrm{acac})_{2}$, indicates that $\mathrm{Fe}$ (III) is a more suitable starting material for the catalyst preparation compared to $\mathrm{Fe}$ (II). Half-wave potential reached to $0.77 \mathrm{~V}$ which is comparable to the most active non-noble metal based ORR catalysts so far [16,17], as well as commercially available Pt/C catalysts [18] The carbon itself did not show good ORR activity and waving curve indicates 2 electron reduction is dominant (Figure S1, black curve). The catalyst without Fe followed 4 electron pathway, but half-wave potential and limiting current were far lower than Fe-N-C catalyst (Figure S1, blue curve).

It was found that proper amounts of Fe in the catalysts are also a critical factor affecting catalyst performance. Catalytic activity initially increased as the amount of Fe increased, possibly due to the increase of active site density, however the activity significantly diminished when Fe was employed over 5 wt. \% (Figure 1b).

Likewise, there was an optimal temperature for heat-treatment. Pyrolysis temperature has been well understood to be a key factor to achieve proper ORR catalysts in several reports $[19,20]$. In these attempts, pyrolysis at $900^{\circ} \mathrm{C}$ yielded a superior ORR catalyst than any other pyrolysis temperature, and both higher and lower temperatures were detrimental to catalytic activity (Figure 1c). Furthermore, an extended heat-treatment time of $4 \mathrm{~h}$ was found to be harmful (Figure 1d). These observations indicate that optimal temperature and duration upon heating considerably affect the formation of active catalytic species in $\mathrm{Fe}_{x} \mathrm{~N}_{y} / \mathrm{NC}$ electrocatalysts. 
To determine the cause of activity difference of the $\mathrm{Fe}_{x} \mathrm{~N}_{y} / \mathrm{NC}$ electrocatalysts obtained under the studied synthetic conditions, $\mathrm{X}$-ray diffraction (XRD) analysis was performed for every catalyst tested. Interestingly, distinct XRD patterns were observed from the catalysts (Figure 2). The characteristic XRD peaks of $\mathrm{Fe}_{3} \mathrm{~N}$ phase [21] centered at $42.8^{\circ}$ (sharp peak), 40.7 $, 37.4^{\circ}, 56.5^{\circ}, 67.6^{\circ}$, and $75.6^{\circ}$ appeared in the catalysts synthesized using $\mathrm{Fe}(\mathrm{acac})_{3}$ or $\mathrm{Fe}(\mathrm{acac})_{2}$ under the standard preparation conditions, i.e., 5 wt. $\% \mathrm{Fe}$ and pyrolysis at $900{ }^{\circ} \mathrm{C}$ for $2 \mathrm{~h}$. Theoretical calculation of several $\mathrm{Fe}_{x} \mathrm{~N}_{y}$ complexes were carried out to identify the most probable structure with the lowest energy (Figure S2). Of the various phases of $\mathrm{Fe}_{x} \mathrm{~N}_{y}$, the only stable phases obtained were those of $\mathrm{FeN}(\mathrm{F} 4-3 \mathrm{~m})$ and $\mathrm{Fe}_{3} \mathrm{~N}\left(\mathrm{P}_{3} 22\right)$. All the others phases were metastable, and decomposed to $\mathrm{FeN}$ and $\mathrm{Fe}_{3} \mathrm{~N}$. A similar trend from the theoretical calculation of the XRD-spectra was observed [22]. Selecting the most optimized structures of $\mathrm{FeN}, \mathrm{Fe}_{2} \mathrm{~N}, \mathrm{Fe}_{3} \mathrm{~N}$ and $\mathrm{Fe}_{4} \mathrm{~N}$, their XRD spectra were simulated and compared with the experimental results as shown in Figure 3.

With regard to the $\mathrm{Fe}_{x} \mathrm{~N}_{y} / \mathrm{NC}$ composites, the combined ORR electrocatalytic test results and XRD analysis revealed that the best-performing active sites contain an $\mathrm{Fe}_{3} \mathrm{~N}\left(\mathrm{P}_{3} 22\right)$ phase on the NCs. The $\mathrm{Fe}_{3} \mathrm{~N}$ phase was not formed in the catalysts prepared using $\mathrm{FeCl}_{3}, \mathrm{FeSO}_{4}$, or ferrocene (Figure 2a), which showed lower ORR activity. These results signify that the $\mathrm{Fe}_{3} \mathrm{~N}$ phase coupled with $\mathrm{NC}$ is the principle structure responsible for efficient ORR in this catalytic system. Analogous results appeared as well in other catalysts prepared under control of other parameters, such as weight percent of $\mathrm{Fe}$, pyrolysis temperature, and time. All the less active catalysts contained less pronounced, or did not contain any, $\mathrm{Fe}_{3} \mathrm{~N}$ XRD structure in their respective XRD spectra (Figure $2 \mathrm{~b}-\mathrm{d}$ ). The catalysts with lower amounts of Fe (i.e., less than $5 \%$ in this study) did not show distinct XRD peaks, indicating that the Fe species were present in an amorphous phase (Figure $2 b$ ). In addition, higher amounts (i.e., higher than $5 \%$ in this study) of Fe contents resulted in the formation of yet another crystal phase that corresponded to metallic Fe (Figure 2b, green).

a)

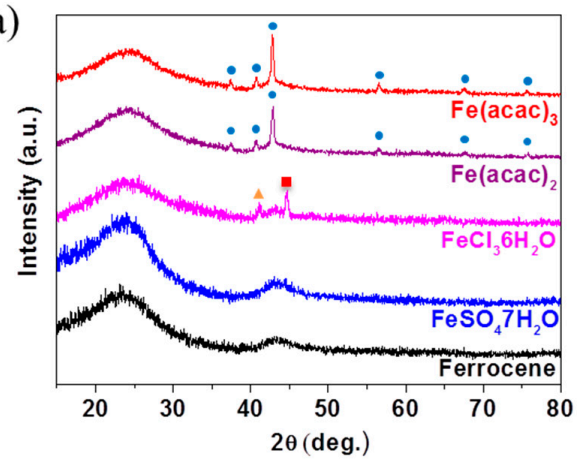

c)

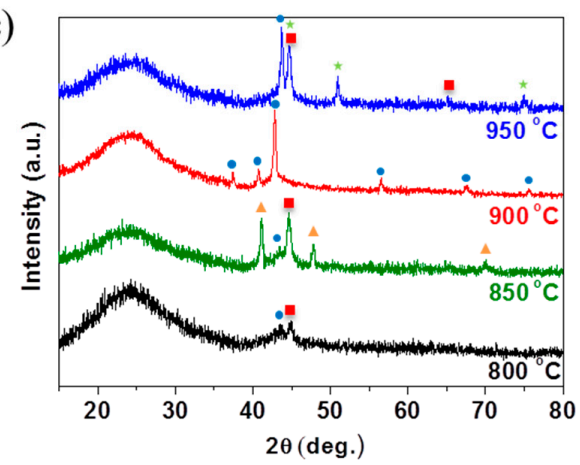

b)

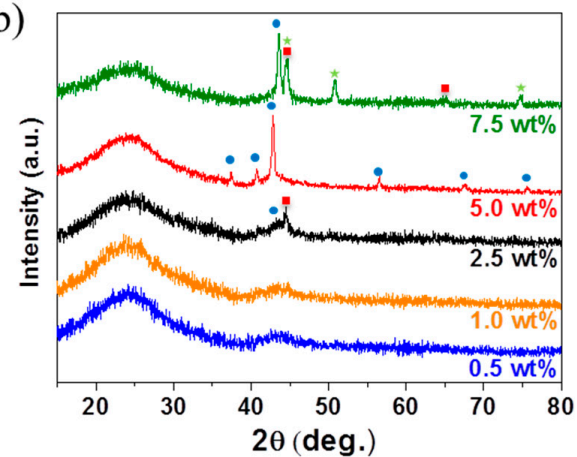

d)

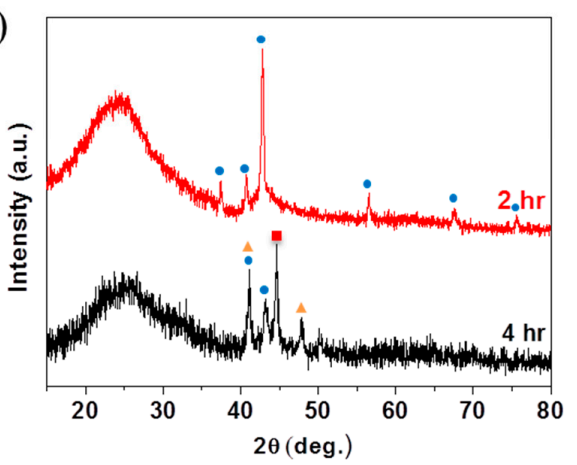

Figure 2. X-ray diffraction (XRD) spectra of Fe-N-C catalysts prepared by altering synthetic conditions. (a) Fe source, (b) Fe contents, (c) pyrolysis temperature, and (d) pyrolysis time. The symbols denote specific Fe species. denotes metallic Fe (JCPDS \# 87-0722), „ denotes FeN (JCPDS \# 50-1087), denotes $\mathrm{Fe}_{3} \mathrm{~N}$ (JCPDS \# 86-0232), and $\boldsymbol{\Delta}$ denotes $\mathrm{Fe}_{4} \mathrm{~N}$ (JCPDS \# 86-0231). 


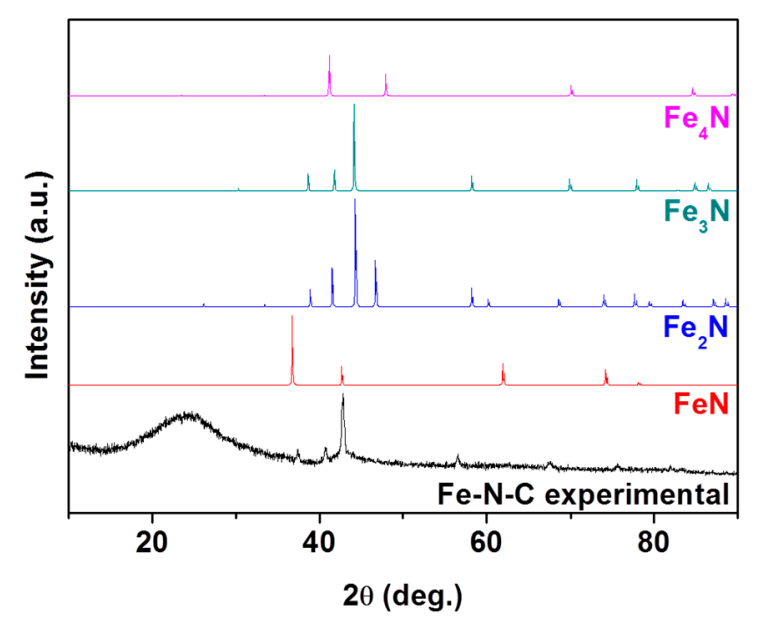

Figure 3. XRD patterns from the experiment compared with the theoretical generated pattern.

The effect of pyrolysis temperature the catalysts ORR activity can also be explained by the presence, or lack thereof, of the $\mathrm{Fe}_{3} \mathrm{~N}$ phase. The $\mathrm{Fe}_{3} \mathrm{~N}$ crystal phase was only found in the catalysts treated at $900{ }^{\circ} \mathrm{C}$. There were both $\mathrm{Fe}_{3} \mathrm{~N}$ and metallic Fe species in the catalysts heated at $800{ }^{\circ} \mathrm{C}$, and $\mathrm{Fe}_{4} \mathrm{~N}$ and metallic Fe species appeared in the catalysts pyrolyzed at $850{ }^{\circ} \mathrm{C}$ and $950{ }^{\circ} \mathrm{C}$, respectively (Figure 2c). Interestingly, the catalyst containing higher Fe contents of $7.5 \mathrm{wt}$. \% and prepared at the higher temperature of $950{ }^{\circ} \mathrm{C}$, possessed an identical metallic Fe species. It is assumed that higher amounts of $\mathrm{Fe}$, combined with high heating temperature, induce an aggregation of Fe nanoparticles to give less active, metallic Fe. Longer reaction time also induced the phase changes of $\mathrm{Fe}_{3} \mathrm{~N}$ to the mixture of $\mathrm{Fe}_{4} \mathrm{~N}$ and metallic Fe (Figure 2d). The strong correlation between the existence of $\mathrm{Fe}_{3} \mathrm{~N}$ phase and ORR performance show that $\mathrm{Fe}_{3} \mathrm{~N}$ is the essential active species for superior ORR performance of iron nitride electrocatalysts.

The presence of $\mathrm{Fe}_{3} \mathrm{~N}$ was likewise observed in transmission electron microscope (TEM) analysis, which showed the characteristic d-spacing $(2.05 \mathrm{~nm})$ of $<111>$ peak of $\mathrm{Fe}_{3} \mathrm{~N}$ phase matched with the experimental d-spacing $(2.10 \mathrm{~nm})$ observed from HRTEM images (Figure 4a). Nanoparticles with an average size of $23.7 \mathrm{~nm}$ were supported on the NC support (Figure $4 \mathrm{~b}$ ). The nanoparticles were determined to be $\mathrm{Fe}_{3} \mathrm{~N}$ by the length of $0.21 \mathrm{~nm}$ of the lattice distance and strong ring pattern corresponding to the (111) phase of $\mathrm{Fe}_{3} \mathrm{~N}$ in a selected area electron diffraction (SAED) (Figure 4c,d).

In addition, fine distribution of $\mathrm{N}$ atoms over the carbon support was evident by EDS mapping (Figure 5). Along with well dispersed $\mathrm{N}$ over the carbon support, a higher population of $\mathrm{N}$ atoms near Fe atoms was observed, which again showed the favorable bonding between $\mathrm{N}$ and Fe to form active catalytic components.

The measured value of the Tafel slope of the single phase $\mathrm{Fe}_{3} \mathrm{~N}$ on $\mathrm{NC}$ catalyst obtained from pyrolysis at $900^{\circ} \mathrm{C}$ was much lower than the corresponding values of the samples containing other iron nitride phases prepared at other conditions: $850{ }^{\circ} \mathrm{C}(61 \mathrm{mV}), 950{ }^{\circ} \mathrm{C}(65 \mathrm{mV})$ and $800{ }^{\circ} \mathrm{C}(69$ $\mathrm{mV}$ ) (Figure 6a). This attests to the effect of the $\mathrm{Fe}_{3} \mathrm{~N}$ species as showing better catalytic performance. Further, the catalytic activity of ORR is closely related to electron transfer mechanism during the reaction [23-25]. Thus, the number of electrons transferred per one mole of oxygen and yield $\mathrm{of}_{\mathrm{HO}_{2}}{ }^{-}$ byproduct were determined by rotational ring disk electrode (RRDE) measurement using the most active $\mathrm{Fe}_{x} \mathrm{~N}_{y} / \mathrm{NC}$ catalyst. The number of transferred electrons was determined to be higher than 3.9 throughout the whole potential range (Figure 6b). This selective and efficient catalytic process supports the high activity of our $\mathrm{Fe}_{3} \mathrm{~N} / \mathrm{NC}$ catalyst. Formation of $\mathrm{HO}_{2}{ }^{-}$was also well inhibited and the amounts did not exceed 5\%. Accelerated durability test (ADT) demonstrated the superior stability of the iron nitride catalyst that showed slight negative shift after 4,000 repeated potential cycles (Figure 6c). 


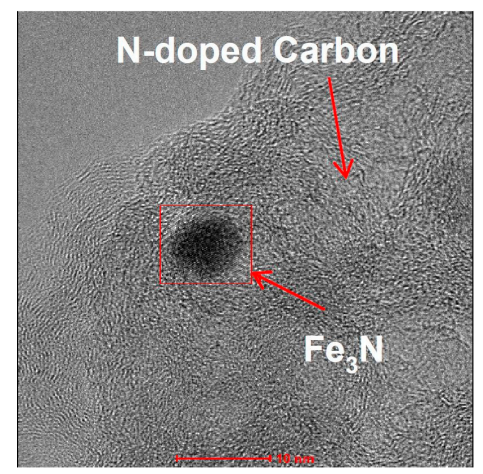

(a)

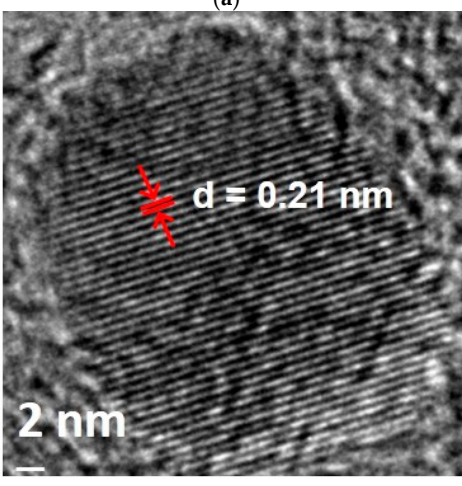

(c)

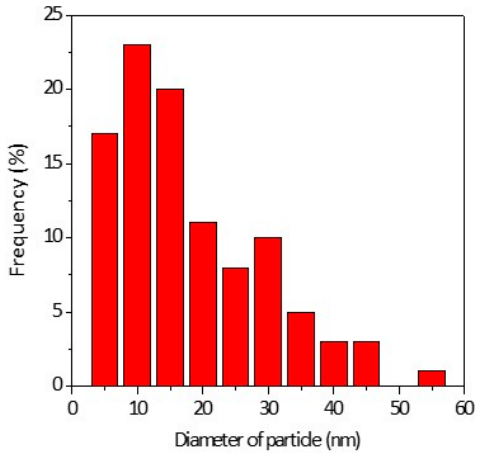

(b)

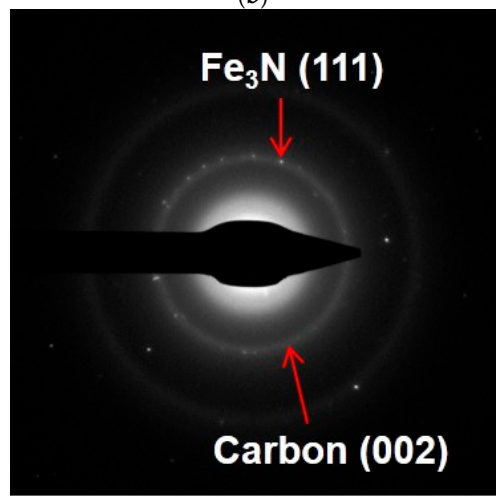

(d)

Figure 4. (a) Transmission electron microscope (TEM) image of Fe-N-C catalyst, (b) particle size distribution of $\mathrm{Fe}_{3} \mathrm{~N}$ nanoparticles in Fe-N-C catalyst, (c) high resolution (HR)-TEM image of $\mathrm{Fe}_{3} \mathrm{~N}$ nanoparticle, and (d) selected area electron diffraction (SAED) image of Fe-N-C catalyst.
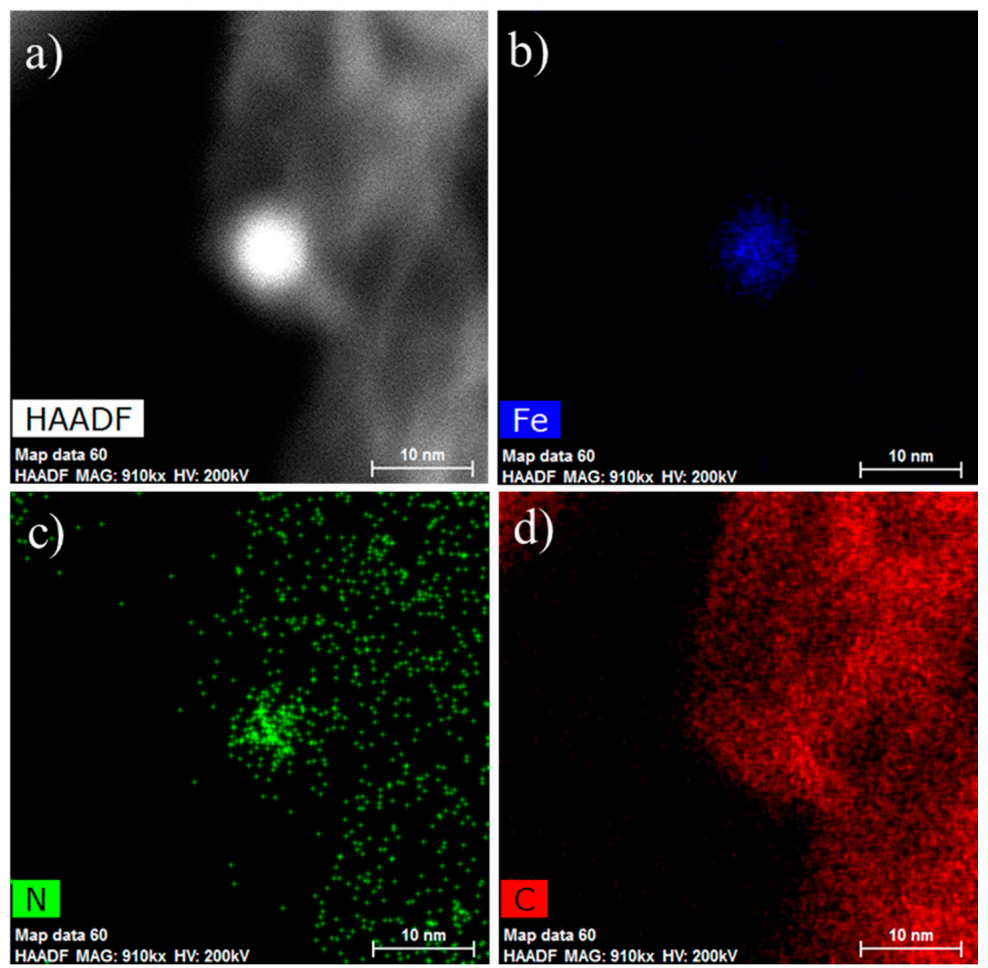

Figure 5. (a) High angle annular dark field-scanning transmission electron microscope (HAADF-STEM) image of Fe-N-C catalyst, electron energy loss spectroscopy (EELS) mapping images of Fe-N-C catalyst (b) $\mathrm{Fe},(\mathbf{c}) \mathrm{N}$, and (d) C. 

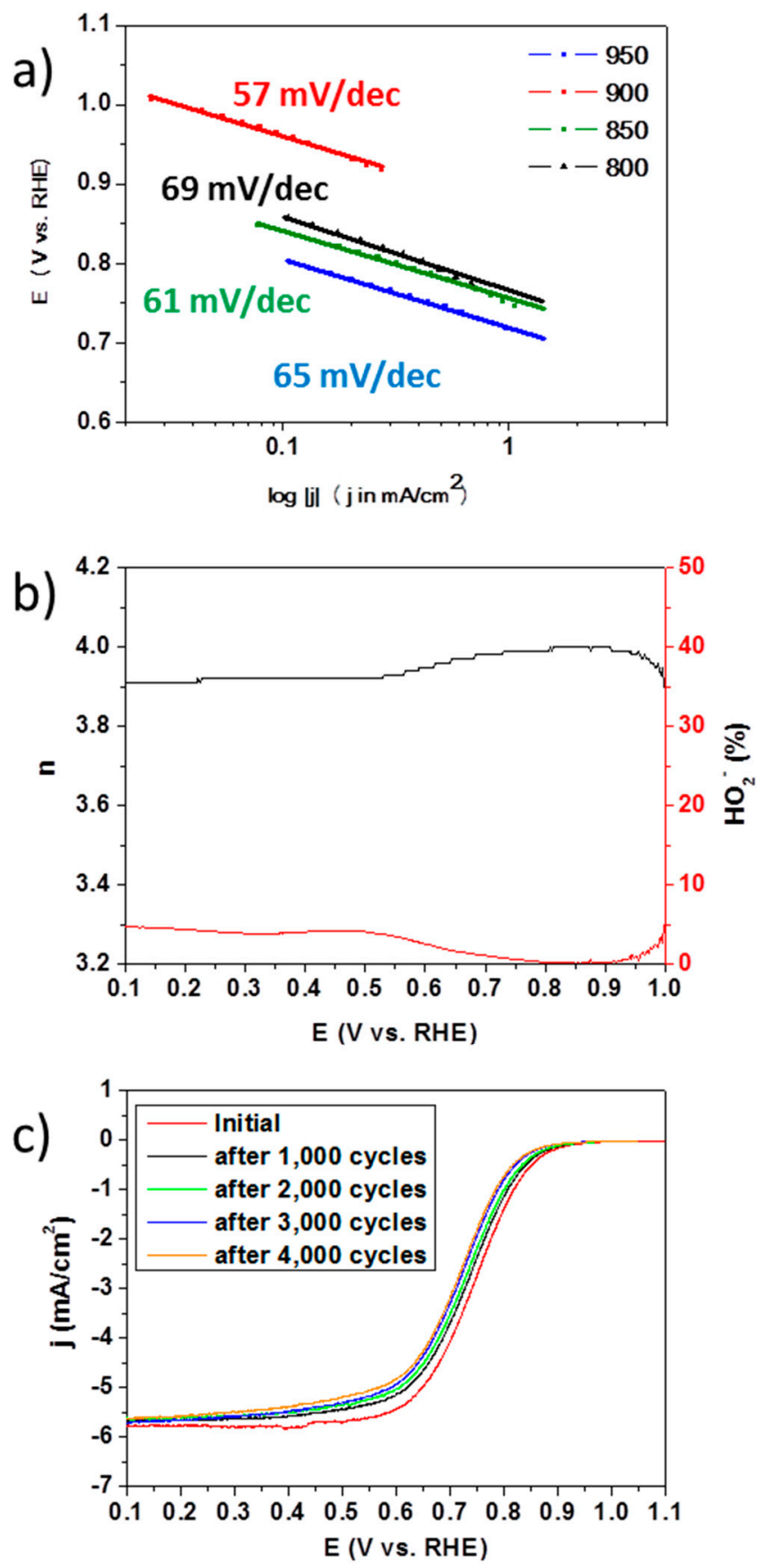

Figure 6. (a) Tafel slopes of the Fe-N-C catalysts prepared by different pyrolysis temperature, (b) number of electron transferred and $\mathrm{HO}_{2}{ }^{-}$yield during the ORR catalyzed by $\mathrm{Fe}-\mathrm{N}-\mathrm{C}$ and (c) accelerated durability testing (ADT) of Fe-N-C; initial, after 1,000, 2,000, 3,000, and 4,000 potential cycles in $\mathrm{O}_{2}$-saturated $0.1 \mathrm{M} \mathrm{KOH}$.

\section{Experimental}

\subsection{Synthesis of $F e_{x} N_{y} / N C$ Catalyst}

All of the chemicals were purchased from Sigma-Aldrich (St. Louis, MO, USA) and used without further purification throughout the entire synthetic procedure. A mixture of Carbon black (Ketjen, Chicago, IL, USA) and Fe salt (iron(III) acetylacetonate, Fe(acac) ${ }_{3}, 5$ wt. \%, Sigma-Aldrich, St. Louis, MO, USA) was ground in a mortar. For the other Fe sources, desired amounts of Fe 
salts such as iron(II) acetylacetonate (Fe(acac) $)_{2}$, Sigma-Aldrich, St. Louis, MO, USA), Iron(III) chloride hexahydrate $\left(\mathrm{FeCl}_{3} \cdot 6 \mathrm{H}_{2} \mathrm{O}, 97 \%\right.$, Sigma-Aldrich, St. Louis, MO, USA), Iron(II) sulfate heptahydrate $\left(\mathrm{FeSO}_{4} \cdot 7 \mathrm{H}_{2} \mathrm{O}, 99 \%\right.$, Sigma-Aldrich, St. Louis, $\mathrm{MO}$, USA), and ferrocene $\left(\mathrm{Fe}\left(\mathrm{C}_{5} \mathrm{H}_{5}\right)_{2}, 98 \%\right.$, Sigma-Aldrich, St. Louis, MO, USA) were employed, instead of $\mathrm{Fe}(\mathrm{acac})_{3}$. The nominal amount was kept at $5.0 \mathrm{wt}$. \% theoretical loading. Subsequently, the powder was annealed at $900{ }^{\circ} \mathrm{C}$ for $2 \mathrm{~h}$ with a ramping rate of $5^{\circ} \mathrm{C} \cdot \mathrm{min}^{-1}$ under $\mathrm{NH}_{3}$ atmosphere. Fe loading, reaction temperature, and pyrolysis time were altered for the optimization of synthetic conditions.

\subsection{Characterization of Catalysts}

Morphology of the as-synthesized catalyst was characterized by high resolution transmission electron microscope (HRTEM, FEI Tecnai F20, FEI, Hillsboro, OR, USA) and high angle annular dark field-scanning transmission electron microscope (HAADF-STEM, FEI Titan at $200 \mathrm{Kv}$, FEI, Hillsboro, OR, USA). Energy dispersive spectrum (EDS) mapping was carried out using a Talos TEM (FEI; Talos F200X 80-200, FEI, Hillsboro, OR, USA) microscope equipped with X-FEG and super-X EDS system with four silicon drift detectors (SDDs) (Bruker, Bermen, Germany) to determine atomic distribution of each element.

\subsection{Electrochemical Measurements}

An Autolab PGSTAT20 potentiostat (Metrohm Autolab B.V., Kanaalweg, Utrecht, The Netherlands) was used to carry out all electrochemical measurements. The experiments were conducted in a standard three-electrode cell and a rotating disk electrode (RDE) system (Eco Chemie B.V., Utrecht, Utrecht, The Netherlands). A saturated calomel electrode (SCE) and Pt wire were selected as the reference and counter electrode, respectively. All potentials were calibrated using a reversible hydrogen electrode (RHE) and reported with respect to the RHE. A glassy carbon (GC) RDE ( $5 \mathrm{~mm}$ in diameter) acted as the working electrode. A rotating ring-disk electrode (RRDE, $5.61 \mathrm{~mm}$ in diameter) was conducted using an AFMSRCE advanced electrochemical system (Pine Instrument Co., Grove City, PA, USA). A three-electrode cell system was employed incorporating a rotating GC disk (disk area: $0.2475 \mathrm{~cm}^{2}$ ) and a Pt ring electrode (ring area: $0.1886 \mathrm{~cm}^{2}$ ) after loading the electrocatalyst as the working electrode. The suspension of the catalytic ink was prepared by ultrasonically dispersing Fe-N-C catalyst in a mixture of Nafion (5 wt. \%, Sigma-Aldrich, St. Louis, MO, USA) and 2-propanol. Then, the amount of the ink slurry $0.464 \mathrm{mg} \cdot \mathrm{cm}^{-2}$ geo of Fe-N-C was loaded onto the GC electrode followed by air-drying. To measure the current of the ORR, linear sweep voltammetry (LSV) was conducted in an $\mathrm{O}_{2}$ saturated $0.1 \mathrm{M} \mathrm{KOH}$ solution with a potential range of 0.05 to $1.1 \mathrm{~V}$ (vs. RHE) and positive scanning rate of $5 \mathrm{mV} \cdot \mathrm{s}^{-1}$ at $1600 \mathrm{rpm}$. The durability of the prepared catalyst was examined by repeating 4,000 potential cycles of cyclic voltammetry (CV) between $0.6 \mathrm{~V}$ and $1.0 \mathrm{~V}$ (vs. RHE) at a scan rate of $100 \mathrm{mV} \cdot \mathrm{s}^{-1}$ in $\mathrm{O}_{2}$-saturated $0.1 \mathrm{M} \mathrm{KOH}$ solution. The peroxide percentage $\left(\% \mathrm{HO}_{2}{ }^{-}\right)$and electron transfer number $(n)$ were evaluated based on the following equations:

$$
\begin{gathered}
n=\frac{4 \times I_{D}}{I_{D}+\frac{I_{R}}{N}} \\
\% H O_{2}^{-}=\frac{200 \times \frac{I_{R}}{N}}{\left(\frac{I_{R}}{N}\right)+I_{D}}
\end{gathered}
$$

In equation (1), $\mathrm{n}$ is the number of electrons transferred per oxygen molecule; IR and ID are the ring and disk current, respectively. The manufacturer's value of $\mathrm{N}$ (ring collection efficiency) is $37 \%$.

The electrochemical measurements on RDE and RRDE greatly depend on the electrode conditions such as the structure, porosity, and geometry of the catalyst layer [26-29]. We tried to minimize those effects by strictly maintaining the standard procedure for electrode preparation. Thus, we suppose that those effects do not alter our catalytic activity comparison. 


\section{Conclusion}

We reported the essential role of $\mathrm{Fe}_{3} \mathrm{~N}$ as the active site for ORR in $\mathrm{Fe}_{x} \mathrm{~N}_{y} / \mathrm{NC}$ catalysts. Several synthetic variables were optimized to obtain a highly active ORR catalyst, and to reveal the relationship between ORR activity and the density of $\mathrm{Fe}_{3} \mathrm{~N}$ sites. The identical patterns in simulated XRD and measured XRD patterns verified the presence of $\mathrm{Fe}_{3} \mathrm{~N}$ phase in the active catalysts. TEM images and SAED patterns further demonstrated the existence of small sized $\mathrm{Fe}_{3} \mathrm{~N}$ nanoparticles on the $\mathrm{N}$ doped carbon material. Numerous parameters such as the type of Fe precursor, Fe contents in the catalyst, pyrolysis temperature, and pyrolysis time affected the formation of the $\mathrm{Fe}_{3} \mathrm{~N}$ nanoparticles. ORR activity of $\mathrm{Fe}_{x} \mathrm{~N}_{y} / \mathrm{NC}$ catalyst was proven to be closely related to the $\mathrm{Fe}_{3} \mathrm{~N}$ phase. The optimized catalyst exhibited excellent ORR activity and durability in alkaline solution. Our effort to identify the active species of iron nitride catalyst for ORR may bring a new opportunity to develop more efficient electrocatalysts and establish a PEMFC based power generation system as well.

Supplementary Materials: The following are available online at www.mdpi.com/2073-4344/6/6/86/s1, Figure S1. Linear sweep Voltammetry curves of ORR in $0.1 \mathrm{M} \mathrm{KOH}$ catalyzed by Fe-N-C, C, and N-C., Figure S2. Calculated formation energy for different $\mathrm{Fe}_{x} \mathrm{~N}_{y}$ compounds.

Acknowledgments: This research was supported by the Technology Development Program to Solve Climate Changes of the Natinal Research Foundation (NRF) funded by the Ministry of Science, ICT, \& Future Planning (NRF-2015M1A2A2056690). This work was supported by the Korean Government through the New and Renewable Energy Core Technology Program of the Korea Institute of Energy Technology Evaluation and Planning (KETEP) funded by MOTIE (No.20133030011320), and the National Research Foundation of Korea Grant funded by MSIP (2016, University-Institute cooperation program). This work was also financially supported by KIST through Institutional Project (2E25411).

Author Contributions: Min Jung Park and Jin Hee Lee contributed equally to this work. They prepared the catalysts and evaluated the electrocatalytic activity of the catalysts. K. P. S. S. Hembram and Sang Soo Han carried out the theoretical calculations and analysis of $\mathrm{Fe}_{x} \mathrm{~N}_{y}$ compounds. Chang Won Yoon and Suk-Woo Nam contributed the interpretation of the analytical data and writing the manuscript. Jin Young Kim provided the concept of this research and managed all the experimental and writing process as the corresponding author.

Conflicts of Interest: The authors declare no conflict of interest.

\section{References}

1. Brian, C.H.S.; Angelika, H. Materials for fuel-cell technologies. Nature 2001, 414, 345-352.

2. Perry, M.L.; Fuller, T.F. A historical perspective of fuel cell technology in the 20th century. J. Electrochem. Soc. 2002, 149, S59-S67. [CrossRef]

3. Nie, Y.; Li, L.; Wei, Z. Recent advancements in Pt and Pt-free catalysts for oxygen reduction reaction. Chem. Soc. Rev. 2015, 44, 2168-2201. [CrossRef] [PubMed]

4. Wang, Y.J.; Zhao, N.; Fang, B.; Li, H.; Bi, X.T.; Wang, H. Carbon-supported Pt-based alloy electrocatalysts for the oxygen reduction reaction in polymer electrolyte membrane fuel cells: Particle size, shape, and composition manipulation and their impact to activity. Chem. Rev. 2015, 115, 3433-3467. [CrossRef] [PubMed]

5. Proietti, E.; Jaouen, F.; Lefevre, M.; Larouche, N.; Tian, J.; Herranz, J.; Dodelet, J.P. Iron-based cathode catalyst with enhanced power density in polymer electrolyte membrane fuel cells. Nat. Commun. 2011, 2, 416. [CrossRef] [PubMed]

6. Hu, Y.; Jensen, J.O.; Zhang, W.; Cleemann, L.N.; Xing, W.; Bjerrum, N.J.; Li, Q. Hollow spheres of iron carbide nanoparticles encased in graphitic layers as oxygen reduction catalysts. Angew. Chem. Int. Ed. 2014, 53, 3675-3679. [CrossRef] [PubMed]

7. Jang-Soo, L.; Gi, S.P.; Sun, T.K.; Meilin, L.; Jaephil, C. A highly efficient electrocatalyst for the oxygen reduction reaction; $n$-doped ketjenblack incorporated into $\mathrm{Fe} / \mathrm{Fe}_{3} \mathrm{C}$-functionalized melamine foam. Angew. Chem. Int. Ed. 2013, 52, 1026-1030.

8. Wen, Z.; Ci, S.; Zhang, F.; Feng, X.; Cui, S.; Mao, S.; Luo, S.; He, Z.; Chen, J. Nitrogen-enriched core-shell structured $\mathrm{Fe} / \mathrm{Fe}_{3} \mathrm{C}-\mathrm{C}$ nanorods as advanced electrocatalysts for oxygen reduction reaction. Adv. Mater. 2012, 24, 1399-1404. [CrossRef] [PubMed] 
9. Xiao, M.; Zhu, J.; Feng, L.; Liu, C.; Xing, W. Meso/macroporous nitrogen-doped carbon architectures with iron carbide encapsulated in graphitic layers as an efficient and robust catalyst for the oxygen reduction reaction in both acidic and alkaline solutions. Adv. Mater. 2015, 27, 2521-2527. [CrossRef] [PubMed]

10. Jang, B.; Bong, S.; Woo, S.; Park, S.K.; Ha, J.; Choi, E.; Piao, Y. Facile synthesis of one-dimensional iron-oxide/carbon hybrid nanostructures as electrocatalysts for oxygen reduction reaction in alkaline media. J. Nanosci. Nanotechnolo. 2014, 14, 8852-8857. [CrossRef]

11. Ma, Y.; Wang, H.; Key, J.; Linkov, V.; Ji, S.; Mao, X.; Wang, Q.; Wang, R. Ultrafine iron oxide nanoparticles supported on $n$-doped carbon black as an oxygen reduction reaction catalyst. Int. J. Hydrogen Energy 2014, 39, 14777-14782. [CrossRef]

12. Tylus, U.; Jia, Q.; Strickland, K.; Ramaswamy, N.; Serov, A.; Atanassov, P.; Mukerjee, S. Elucidating oxygen reduction active sites in pyrolyzed metal-nitrogen coordinated non-precious-metal electrocatalyst systems. J. Phys. Chem. C 2014, 118, 8999-9008. [CrossRef] [PubMed]

13. Palaniselvam, T.; Kannan, R.; Kurungot, S. Facile construction of non-precious iron nitride-doped carbon nanofibers as cathode electrocatalysts for proton exchange membrane fuel cells. Chem. Commun. 2011, 47, 2910-2912. [CrossRef] [PubMed]

14. Yin, H.; Zhang, C.; Liu, F.; Hou, Y. Hybrid of iron nitride and nitrogen-doped graphene aerogel as synergistic catalyst for oxygen reduction reaction. Adv. Funct. Mater. 2014, 24, 2930-2937. [CrossRef]

15. Zhang, J.; He, D.; Su, H.; Chen, X.; Pan, M.; Mu, S. Porous polyaniline-derived $\mathrm{FeN}_{x} \mathrm{C} / \mathrm{C}$ catalysts with high activity and stability towards oxygen reduction reaction using ferric chloride both as an oxidant and iron source. J. Mater. Chem. A 2014, 2, 1242-1246. [CrossRef]

16. Michel, L.; Eric, P.; Frédéric, J.; Jean-Pol, D. Iron-based catalysts with improved oxygen reduction activity in polymer electrolyte fuel cells. Science 2009, 324, 71-74.

17. Wu, G.; More, K.L.; Johnston, C.M.; Zelenay, P. High-performance electrocatalysts for oxygen reduction derived from polyaniline, iron, and cobalt. Science 2011, 332, 443-447. [CrossRef] [PubMed]

18. Ganesan, S.; Leonard, N.; Barton, S.C. Impact of transition metal on nitrogen retention and activity of iron-nitrogen-carbon oxygen reduction catalysts. Phys. Chem. Chem. Phys. 2014, 16, 4576-4585. [CrossRef] [PubMed]

19. Hung, T.F.; Tu, M.H.; Tsai, C.W.; Chen, C.J.; Liu, R.S.; Liu, W.R.; Lo, M.Y. Influence of pyrolysis temperature on oxygen reduction reaction activity of carbon-incorporating iron nitride/nitrogen-doped graphene nanosheets catalyst. Int. J. Hydrogen Energy 2013, 38, 3956-3962. [CrossRef]

20. Peng, H.; Mo, Z.; Liao, S.; Liang, H.; Yang, L.; Luo, F.; Song, H.; Zhong, Y.; Zhang, B. High performance Fe- and $n$-doped carbon catalyst with graphene structure for oxygen reduction. Sci. Rep. 2013. [CrossRef]

21. Schnepp, Z.; Thomas, M.; Glatzel, S.; Schlichte, K.; Palkovits, R.; Giordano, C. One pot route to sponge-like $\mathrm{Fe}_{3} \mathrm{~N}$ nanostructures. J. Mater. Chem. 2011, 21, 17760-17764. [CrossRef]

22. Jain, A.; Ong, S.P.; Hautier, G.; Chen, W.; Richards, W.D.; Dacek, S.; Cholia, S.; Gunter, D.; Skinner, D.; Ceder, G.; et al. Commentary: The materials project: A materials genome approach to accelerating materials innovation. APL Mater. 2013, 1, 011002. [CrossRef]

23. Kattel, S.; Atanassov, P.; Kiefer, B. A density functional theory study of oxygen reduction reaction on non-PGM Fe-N $x$-C electrocatalysts. Phys. Chem. Chem. Phys. 2014, 16, 13800-13806. [CrossRef] [PubMed]

24. Kramm, U.I.; Herranz, J.; Larouche, N.; Arruda, T.M.; Lefevre, M.; Jaouen, F.; Bogdanoff, P.; Fiechter, S.; Abs-Wurmbach, I.; Mukerjee, S.; et al. Structure of the catalytic sites in Fe/N/C-catalysts for $\mathrm{O}_{2}$-reduction in PEM fuel cells. Phys. Chem. Chem. Phys. 2012, 14, 11673-11688. [CrossRef] [PubMed]

25. Szakacs, C.E.; Lefevre, M.; Kramm, U.I.; Dodelet, J.P.; Vidal, F. A density functional theory study of catalytic sites for oxygen reduction in $\mathrm{Fe} / \mathrm{N} / \mathrm{C}$ catalysts used in $\mathrm{H}_{2} / \mathrm{O}_{2}$ fuel cells. Phys. Chem. Chem. Phys. 2014, 16, 13654-13661. [CrossRef] [PubMed]

26. Masa, J.; Batchelor-McAuley, C.; Schuhmann, W.; Compton, R.G. Koutecky-levich analysis applied to nanoparticle modified rotating disk electrodes: Electrocatalysis or misinterpretation. Nano. Res. 2013, 7, 71-78. [CrossRef]

27. Ward, K.R.; Gara, M.; Lawrence, N.S.; Hartshorne, R.S.; Compton, R.G. Nanoparticle modified electrodes can show an apparent increase in electrode kinetics due solely to altered surface geometry: The effective electrochemical rate constant for non-flat and non-uniform electrode surfaces. J. Electroanal. Chem. 2013, 695, 1-9. [CrossRef] 
28. Gara, M.; Ward, K.R.; Compton, R.G. Nanomaterial modified electrodes: Evaluating oxygen reduction catalysts. Nanoscale 2013, 5, 7304-7311. [CrossRef] [PubMed]

29. Ward, K.R.; Compton, R.G. Quantifying the apparent 'catalytic' effect of porous electrode surfaces. J. Electroanal. Chem. 2014, 724, 43-47. [CrossRef]

(C) 2016 by the authors; licensee MDPI, Basel, Switzerland. This article is an open access article distributed under the terms and conditions of the Creative Commons Attribution (CC-BY) license (http:/ / creativecommons.org/licenses/by/4.0/). 